\title{
Short report: relationship between restricted and repetitive behaviours in children with autism spectrum disorder and their parents
}

\author{
Mirko Uljarević ${ }^{1,4^{*}}$, David W. Evans², Gail A. Alvares ${ }^{3}$ and Andrew J. O. Whitehouse ${ }^{3}$
}

\begin{abstract}
Background: Restricted and repetitive behaviours (RRBs) constitute a core symptom domain of autism spectrum disorder (ASD). However, the nature of RRBs in the context of the Broader Autism Phenotype (BAP) is not well understood. In particular, the relationship between RRBs in ASD probands and their parents remains largely unexplored. The current study explored the link between parental RRBs, measured via Interest in Patterns and Resistance to Changes subscales of the Autism Quotient and their children's RRBs, measured via Autism Diagnostic Observation Schedule RRB standardized domain score.

Findings: Having both parents within the top $20 \%$ of their RRB scores was associated with an increase of RRB scores for their children; however, no parent-of-origin effects were identified. Although the trend was observed for both Interest in Patterns and Resistance to Changes subscale, it was only statistically significant for Interest in Patterns.

Conclusions: This paper provides significant contribution to our understanding of association between RRBs in parents and their children with ASD. Future work should also address the BAP in distinct genetic subtypes (whole chromosome aneuploidies, single gene mutations, copy number variations) of neurodevelopmental and neuropsychiatric disorders that involve RRBs.
\end{abstract}

Keywords: Autism, Repetitive behaviours, Broader Autism Phenotype, Parents

\section{Background}

Autism spectrum disorder (ASD) is a behaviourally defined cluster of neurodevelopmental conditions considered to be amongst the most heritable complex neuropsychiatric disorders. Family and twin studies suggest that the recurrence rate of ASD between siblings is between 3 and $14 \%$ [1] and that the concordance of ASD is $58 \%$ for male and $60 \%$ for female monozygotic and $21 \%$ for male and $27 \%$ for female dizygotic pairs [2]. Since the original descriptions by Kanner [3] and Asperger [4], it has been recognized

\footnotetext{
* Correspondence: M.Uljarevic@latrobe.edu.au

${ }^{1}$ Olga Tennison Autism Research Centre, School of Psychology and Public Health, La Trobe University, Bundora, Victoria 3086, Australia

${ }^{4}$ Cooperative Research Centre for Living with Autism (Autism CRC), Long Pocket, Brisbane, Queensland, Australia

Full list of author information is available at the end of the article
}

that family members of affected individuals-in particular parents-in addition to having high recurrence of categorical ASD diagnosis, show traits and behaviours that are qualitatively similar to those seen in ASD, but less severe. This presence of ASD traits exhibited to a lesser degree is commonly referred to as the Broader Autism Phenotype (BAP) [5, 6].

Previous research has mainly concentrated on the socio-communicative aspects of the BAP. When compared to family members of control individuals, relatives of individuals with ASD, from high infant siblings to parents, tend to show higher levels of language, communication, social interaction, and cognition difficulties $[7,8]$. Evidence of familiality and inter-generational transmission of these traits has also been reported [9-12].

Restricted and repetitive behaviours (RRBs) constitute a core symptom domain of ASD. However, while RRBs 
represent one of two core symptom clusters in the the 5th edition of the Diagnostic and Statistical Manual of Mental Disorders criteria for ASD (DSM-5) [13], the nature of RRB in the context of the BAP is not well understood. Research to date suggests elevated levels of RRBs in unaffected family members. However, most studies have used measures that assess personality traits and activities that are indicative of potential RRBs [14-17] rather than dedicated RRB measures $[18,19]$. Although several studies have explored evidence for familiality of RRBs amongst affected siblings with ASD and high risk siblings without the disorder [20-24], the relationship between RRBs in ASD probands and their parents remains largely unexplored. The paucity of data on the associations between RRBs in ASD probands and their parents is a significant limitation in the scholarly literature. The only exception is a study by Smith et al. [25] who found that intense preoccupations (as measured via ADI-R) in ASD probands were associated with rigidity and aloofness in their fathers; however, as with studies reviewed above, Smith and colleagues have used parental personality traits as a proxy of RRBs rather than a dedicated measure.

The current study explored relationships between parental and proband RRBs. Based on evidence from studies of socio-communicative behaviours, we hypothesized that higher RRBs scores in parents would be associated with higher levels of RRBs in their children diagnosed with ASD, but not in higher levels of sociocommunicative problems. We made no specific predictions in terms of the parent-of-origin effect.

\section{Methods}

\section{Participants}

One hundred and sixty-nine mother-father-child with ASD triads (mother, $M_{\text {age }}=39.73$ years, $\mathrm{SD}_{\text {age }}=6.38$; father, $M_{\text {age }}=41.76$ years, $\mathrm{SD}_{\text {age }}=6.82$; child, $M_{\text {age }}=$ 8.03 years, $\mathrm{SD}_{\text {age }}=3.91$, range, $2.43-17.8,138$ males) participated as a part of the Western Australian Autism Biological Registry (WAABR) study. All children had a community diagnostic assessment conducted by a multidisciplinary team comprising a paediatrician, clinical psychologist, and speech pathologist, leading to a best-estimate clinical diagnosis of an ASD. At their research appointment for WAABR, the child's diagnosis was verified using the Autism Diagnostic Observation Schedule-Generic (ADOS-G) [26].

\section{Procedures and measures}

The study was approved by the Princess Margaret Hospital Human Research Ethics Committee, and all participants have provided informed consent. Parents were mailed the Autism Spectrum Quotient (AQ) [27] as a part of a series of questionnaires included in the WAABR study. Families then attended the Telethon Kids Institute in Perth, Western Australia, where the ADOS-G was administered by the same trained and research-reliable assessor.

The AQ is a self-report questionnaire designed to measure levels of autistic-like traits. In this study, we have used Interest in Patterns (IP; five items, example item: 'I like to collect information about categories of things'; Cronbach's $\alpha=.71$ ) and Resistance to Change (RC; five items, 'I prefer to do things the same way over and over again'; Cronbach's $\alpha=.73$ ) factors identified by Lau et al. [28] in a sample of Australian adults with and without ASD as measures of parental RRBs.

The ADOS-G is a clinician-administered observational assessment developed as a standardized classification of ASD. Forty-nine children were administered ADOS-G module 1, 62 Module 2, 55 Module 3, and 3 Module 4. We have used standardized ADOS-G scores for the social affect (SA) and RRBs domains following Hus et al. [29], as these scores can be used across individuals of different developmental levels.

\section{Results}

RRB scores between probands whose mother or father had elevated RRB scores were first compared in order to explore potential parent-of-origin effects. Following the methodology used by Lyall et al. [12], elevated RRB scores in parents (IP and RC were considered separately) were defined as the top $20 \%$ of the score distribution for mothers and fathers, respectively. There was no evidence of parent-of-origin effect when either IP $U=335.5, z=-.378, p=.705$ or $\mathrm{RC} U=463.5, z=-.007$, $p=.994$ scores were used to stratify the sample into children whose only mother had scores in the top $20 \%$. Mann-Whitney $U$ test revealed no significant difference in ADOS RRB scores between male and female probands $U=2133.5, z=-.023, p=.982$. For these reasons, we partitioned ASD probands based on whether neither parent had elevated RRB scores, one parent (either mother or father) had elevated RRB scores, or both parents had had elevated RRB scores. As can be seen from the Table 1, when probands were grouped based on their parental IP scores, there was a significant difference on ADOS RRBs $(p=.018)$.

Although a similar trend was observed when RC parental scores were used to group ASD probands, there were no significant differences between groups in terms of $\mathrm{ADOS} \operatorname{RRB}(p=53)$. No significant differences in terms of ADOS SA scores were observed, either when parental IP $(p=.62)$ or RC scores $(p=.62)$ were used as a grouping variable. 
Table 1 Means (and SDs) ADOS standardized domain scores as a function of parental RRB status

\begin{tabular}{|c|c|c|c|c|c|c|c|}
\hline & \multicolumn{3}{|c|}{ Parent with elevated RRB traits } & \multirow[b]{2}{*}{$x^{2}$} & \multirow[b]{2}{*}{$p$} & \multirow[b]{2}{*}{$\omega^{2}$} & \multirow[b]{2}{*}{ Post hoc (Mann-Whitney $U$ ) } \\
\hline & Neither $(N ; N=96)$ & Either $(E ; N=53)$ & Both $(B ; N=18)$ & & & & \\
\hline \multicolumn{8}{|c|}{ AQ Interest in Patterns } \\
\hline ADOS SA & $7.52(2.07)$ & $7.28(2.13)$ & $7.83(1.82)$ & .960 & .62 & 0 & NS \\
\hline ADOS RRBS & $3.98(2.35)$ & $4.42(2.56)$ & $5.67(2.19)$ & 8.08 & .018 & .03 & $\mathrm{~B}>\mathrm{N}(p=.002)$ \\
\hline \multicolumn{8}{|c|}{ AQ Resistance to Change } \\
\hline ADOS SA & $7.44(2.21)$ & $7.41(1.95)$ & $8(1.56)$ & .94 & .62 & 0 & NS \\
\hline ADOS RRBS & $4.13(2.33)$ & $4.38(2.52)$ & $5(2.8)$ & 1.25 & .53 & 0 & NS \\
\hline
\end{tabular}

Note: elevated RRB traits are defined as the top $20 \%$ of the score distribution

\section{Discussion}

The current study explored the link between parental RRBs, measured via Interest in Patterns and Resistance to Changes subscales of the AQ and their children's RRBs, measured via ADOS RRB standardized domain score. Having both parents within the top 20th percentile of their RRB scores was associated with an increase of ADOS RRB scores for their children; however, no parent-of-origin effects were identified. Although the trend was observed for both IP and RC RRBs, it was only significant for IP but not for RC. This finding is broadly in line with findings by Smith et al. [25] who reported that increased IP but not RC in ASD probands were associated with parental personality traits indicative of RRBs. In line with the current understanding of the ASD traits as being fractionable at the genetic level [30], no such trend was observed for the social affect ADOS domain.

Our study had an advantage of using observational measure of RRBs in children rather than parental report, thus avoiding potential issues related to shared method variance and reporter bias. Another advantage was using measures that assess RRBs in both parents and their children, rather than personality, as has been the case in the only study to date that has explored the relationship between RRBs in probands with ASD and their parents [25]. However, both ADOS and AQ are limited in their sampling of RRBs. The AQ reflects only what can be considered 'high level' (i.e. compulsive behaviour) RRBs, whereas the ADOS-G provides only an overall score for RRBs. Furthermore, although the observational context that ADOS provides is conducive to noting motor stereotypes and some sensory interests, it is limited in its ability to assess more complex restricted patterns of interest and rigid types of behaviours/insistence on sameness. For assessing these behaviours, sampling across time and contexts is necessary. This limited sampling is a significant issue as, despite all RRBs being linked by underlying problems of rigidity, repetitiveness, invariance and inappropriateness, they are an extremely heterogeneous group ranging from simple motor tics to extremely complex patterns of routinized behaviours and interests. Therefore, it has been suggested that RRBs should be treated as multidimensional construct that encompasses several related but distinct behavioural categories [31, 32].

Instruments designed for purposes of screening and diagnosis of ASD are limited by concentrating only on behaviours considered to be specific to ASD despite RRBs cutting across a various wide range of neurodevelopmental, neuropsychiatric and neurological disorders (e.g. schizophrenia, obsessive-compulsive disorder, Parkinson disease, Sydenham chorea, Tourette syndrome, ASD; [32]) and RRBs also being present during typical development [33-35]. It has been argued (for example, Research Domain Criteria (RDoC); [36]) that rather than studying particular behaviours within categorically defined clinical diagnoses, it is necessary to study these behaviours across both typical development and disorders in order to be able to identify their genetic, neural underpinnings and mechanisms. In order to achieve this, RRB measures need to be comprehensive enough to gather information on a wide range of behaviours that are not exclusive to any particular disorder, be appropriate for use across the lifespan, and be sensitive enough to identify mild variants of symptom expression. Although reliable measures of RRBs such as the Repetitive Behaviour Qestionnaire-2 [35, 37] and Repetitive Behaviour Scale-Revised [Bodfish JW, Symons FW, Lewis MH. The Repetitive Behavior Scale. Western Carolina Center Research Reports (unpublished). 1999] are available, they do not meet these criteria. Development of quantitative trait assessment tools for RRBs is therefore a key for future research.

\section{Conclusion}

This paper provides significant contribution to our understanding of association between RRBs in parents and their children with ASD. The data extend previous research by using dedicated RRB measures for both parents and children. Further research will need to explore the pattern of inter-generational transmission of different types of RRBs across both normative development and clinical condition using reliable, quantitative trait measures of RRBs. Future work should also address the BAP in distinct genetic subtypes (whole chromosome 
aneuploidies, single gene mutations, copy number variations) of neurodevelopmental and neuropsychiatric disorders that involve RRBs.

\section{Abbreviations}

ADOS, Autism Diagnostic Observation Schedule; AQ, Autism Spectrum Quotient; ASD, autism spectrum disorder; BAP, Broader Autism Phenotype; IP, Interest in Patterns; RC, Resistance to Changes; RRBs, restricted and repetitive behaviours; WAABR, Western Australian Autism Biological Registry

\section{Acknowledgements}

We deeply appreciate the support and time given by the parents and children who were involved in the research. We thank Ms Anna Hunt and Alexandra Woolacott for their help with data preparation.

\section{Funding}

MU and GAA are funded by the Cooperative Research Centre for Living with Autism (Autism CRC), established and supported under the Australian Government's Cooperative Research Centres Program; AJOW is supported by a NHMRC Senior Research Fellowship (APP1077966); DWE has no support or funding related to this study to report.

\section{Authors' contributions}

AJOW and GAA were responsible for the data collection. MU, DWE and AJOW performed the data analysis. MU, DWE, AJOW and GAA participated in the interpretation of data. (MU, DWE, AJOW, GAA). MU drafted the initial manuscript. All authors have provided comments on the initial draft and approved the final version.

\section{Competing interests}

The authors declare that they have no competing interests.

\section{Ethics approval and consent to participate}

The study was approved by the Princess Margaret Hospital Human Research Ethics Committee, and all participants have provided informed consent.

\section{Author details}

${ }^{1}$ Olga Tennison Autism Research Centre, School of Psychology and Public Health, La Trobe University, Bundora, Victoria 3086, Australia. ${ }^{2}$ Department of Psychology, Bucknell University, Lewisburg, PA, USA. ${ }^{3}$ Telethon Kids Institute, University of Western Australia, Perth, WA, Australia. ${ }^{4}$ Cooperative Research Centre for Living with Autism (Autism CRC), Long Pocket, Brisbane, Queensland, Australia.

Received: 4 January 2016 Accepted: 5 June 2016

Published online: 14 June 2016

\section{References}

1. Ozonoff S, Young G, Carter A, Messinger D, Yirmiya N, Zwaigenbaum L, Bryson S, Carver LJ, Constantino JN, Dobkins K, Hutman T, Iverson JM, Landa R, Rogers SJ, Sigman M, Stone WL. Recurrence risk for autism spectrum disorders: a Baby Siblings Research Consortium study. Pediatrics. 2011;128: e488-95.

2. Hallmayer J, Cleveland S, Torres A, Phillips J, Cohen B, Torigoe T, Miller J, Fedele A, Collins J, Smith K, Lotspeich L, Croen LA, Ozonoff S, Lajonchere C, Grether JK, Risch N. Genetic heritability and shared environmental factors among twin pairs with autism. Arch Gen Psychiatry. 2011;68(11):1095-102.

3. Kanner L. Autistic disturbances of affective contact. Nervous Child. 1943 2:217-50.

4. Asperger H. 'Autistic psychopathy' in childhood. In: U. Frith, editor. Autism and Asperger Syndrome. Cambridge: Cambridge University Press; 1991. p. 37-92)

5. Piven J, Palmer P, Landa R, Santangelo S, Jacobi D, Childress D. Personality and language characteristics in parents from multiple-incidence autism families. Am J Med Genet. 1997;74:398-411.

6. Bailey A, Palferman S, Heavey L, Le Couteur A. Autism: the phenotype in relatives. J Autism Dev Disord. 1998;28(5):369-92.

7. Gerdts J, Bernier R. The broader autism phenotype and its implications on the etiology and treatment of autism spectrum disorders. Autism Res Treat. 2011;2011:545901.
8. Sucksmith E, Roth RA, Hoekstra A. Autistic traits below the clinical threshold: re-examining the broader autism phenotype in the 21 st century. Neuropsychol Rev. 2011;21(4):360-89.

9. Bishop DVM, Maybery M, Wong D, Maley A, Hallmayer J. Characteristics of the broader phenotype in autism: a study of siblings using the Children's Communication Checklist- 2. Am J Med Genet B Neuropsychiatr Genet. 2006;141B:117-22.

10. Whitehouse AJO, Barry JG, Bishop DVM. The broader language phenotype of autism: a comparison with specific language impairment. J Child Psychol Psychiatry. 2007:48(8):822-30.

11. Taylor L, Maybery M, Wray J, Ravine D, Hunt A, Whitehouse A. Brief report: do the nature of communication impairments in autism spectrum disorders relate to the broader autism phenotype in parents? J Autism Dev Disord. 2013;43(12):2984-9.

12. Lyall K, Constantino JN, Weisskopf MG, Roberts AL, Ascherio A, Santangelo SL. Parental social responsiveness and risk of autism spectrum disorder in offspring. JAMA Psychiatry. 2014:71(8):936-42.

13. American Psychiatric Association. Diagnostic and Statistical Manual of Mental Disorders. 5th ed. Arlington: American Psychiatric Publishing; 2013.

14. Losh M, Childress D, Lam K, Piven J. Defining key features of the broad autism phenotype: a comparison across parents of multiple- and singleincidence autism families. Am J Med Genet B Neuropsychiatr Genet. 2008; 147B(4):424-33.

15. Narayan S, Moyes B, Wolff S. Family characteristics of autistic children-a further report. J Autism Dev Disord. 1990;20(4):523-35.

16. Wolff S, Narayan S, Moyes B. Personality characteristics of parents of autistic children: a controlled study. J Child Psychol Psychiatry. 1988;29(2):143-53.

17. Seidman I, Yirmiya N, Milshtein S, Ebstein RP, Levi S. The Broad Autism Phenotype Questionnaire: mothers versus fathers of children with an autism spectrum disorder. J Autism Dev Disord. 2012:42(5):837-46.

18. Piven J, Palmer P, Jacobi D, Childress D, Arndt S. Broader autism phenotype: evidence from a family history study of multiple-incidence autism families. Am J Psychiatry. 1997;154(2):185-90.

19. Christensen L, Hutman T, Rozga A, Young GS, Ozonoff S, Rogers SJ. Play and developmental outcomes in infant siblings of children with autism. J Autism Dev Disord. 2010:40:946-57.

20. Cuccaro ML, Shao Y, Grubber J, Slifer M, Wolpert CM, Donnelly SL, et al. Factor analysis of restricted and repetitive behaviors in autism using the Autism Diagnostic Interview-R. Child Psychiatry Hum Dev. 2003;34:3-17.

21. Silverman JM, Smith CJ, Schmeidler J, Hollander E, Lawlor BA, Fitzgerald M, et al. Symptom domains in autism and related conditions: evidence for familiality. Am J Med Genet. 2002;114:64-73.

22. Kolevzon A, Smith CJ, Schmeidler J, Buxbaum JD, Silverman JM. Familial symptom domains in monozygotic siblings with autism. Am J Med Genet B Neuropsychiatr Genet. 2004;129:76-81.

23. Szatmari P, Georgiades S, Bryson S, Zwaigenbaum L, Roberts W, Mahoney W, et al. Investigating the structure of the restricted, repetitive behaviours and interests domain of autism. J Child Psychol Psychiatry. 2006;47:582-90

24. Wolff JJ, Botterton KN, Dager SR, Elison JT, Estes AM, Gu H, Piven J. Longitudinal patterns of repetitive behavior in toddlers with autism. JChild Psychol Psychiatry. 2014;55(8):945-53.

25. Smith CJ, Lang CM, Kryzak L, Reichenberg A, Hollander E, Silverman JM Familial associations of intense preoccupations, an empirical factor of the restricted, repetitive behaviors and interests domain of autism. J Child Psychol Psychiatry. 2009;50(8):982-90.

26. Lord C, Rutter M, DiLavore PC, Risi S. Autism diagnostic observation schedule_-generic. California: Western Psychological Services; 2000.

27. Baron-Cohen S, Wheelwright S, Skinner R, Martin J, Clubley E. The AutismSpectrum Quotient (AQ): evidence from Asperger Syndrome/highfunctioning autism, males and females, scientists and mathematicians. J Autism Dev Disord. 2001;31(1):5-17.

28. Lau WYP, Kelly AB, Peterson CC. Further evidence on the factorial structure of the Autism Spectrum Quotient (AQ) for adults with and without a clinical diagnosis of autism. J Autism Dev Disord. 2012;43(12):2807-15.

29. Hus V, Gotham K, Lord C. Standardizing ADOS domain scores: separating severity of social affect and restricted and repetitive bevaviors. J Autism Dev Disord. 2014:44:2400-12.

30. Happe F, Ronald A. The "fractionable autism triad": a review of evidence from behavioural, genetic, cognitive and neural research. Neuropsychol Rev. 2008;18:287-304. 
31. Leekam SR, Prior MR, Uljarevic M. Restricted and repetitive behaviors in autism spectrum disorders: a review of research in the last decade. Psychol Bull. 2011;137(4):562-93.

32. Langen M, Durston $\mathrm{S}$, Kas MJH, van Engeland H, Staal WG. The neurobiology of repetitive behavior: ... and men. Neurosci Biobehav Rev. 2011;35(3):356-65.

33. Arnott B, McConachie H, Meins E, Fernyhough C, Le Couteur A, Turne M, Leekam $\mathrm{S}$. The frequency of restricted and repetitive behaviors in a community sample of 15-month-old infants. J Dev Behav Pediatr. 2010;31: 223-9.

34. Evans DW, Leckman JF, Carter A, Reznick JS, Henshaw D, King RA, Pauls D. Ritual, habit, and perfectionism: the prevalence and development of compulsive-like behavior in normal young children. Child Dev. 2010;68:58-68.

35. Leekam SR, Tandos J, McConachie H, Meins E, Parkinson K, Wright C, Le Couteur A. Repetitive behaviours in typically developing 2 year olds. Journal of Child Psychology and Psychiatry. 2007:48(11):1131-8.

36. Insel TR, Cuthbert BN, Garvey MA, Heinssen RK, Pine DS, Quinn KJ, et al. Research domain criteria (RDoC): toward a new classification framework for research on mental disorders. Am J Psychiatr. 2010;167:748-51.

37. Barrett SL, Uljarevic M, Baker EK, Richdale AL, Jones CRG, Leekam SR. The Adult Repetitive Behaviours Questionnaire-2 (RBQ-2A): a self-report measure of restricted and repetitive behaviours. J Autism Dev Disord. 2015;45(11):1-13.

\section{Submit your next manuscript to BioMed Central} and we will help you at every step:

- We accept pre-submission inquiries

- Our selector tool helps you to find the most relevant journal

- We provide round the clock customer support

- Convenient online submission

- Thorough peer review

- Inclusion in PubMed and all major indexing services

- Maximum visibility for your research

Submit your manuscript at www.biomedcentral.com/submit

) Biomed Central 